\title{
Low dose radiation prevents doxorubicin-induced cardiotoxicity
}

\author{
Xin Jiang ${ }^{1, *}$, Yaqiong Hong ${ }^{1, *}$, Di Zhao ${ }^{1}$, Xinxin Meng ${ }^{1}$, Lijing Zhao ${ }^{2}$, Yanwei Du${ }^{3}$, \\ Zan Wang ${ }^{4}$, Yan Zheng ${ }^{5}$, Lu Cai ${ }^{6}$ and Hongyu Jiang ${ }^{1}$ \\ ${ }^{1}$ Department of Health Examination Center, The First Hospital of Jilin University, Changchun, Jilin 130021, China \\ ${ }^{2}$ The School of Basic Medicine, Jilin University, Changchun, Jilin 130021, China \\ ${ }^{3}$ Changchun University of Chinese Medicine, Changchun, Jilin 130021, China \\ ${ }^{4}$ Department of Internal Neurology, The First Hospital of Jilin University, Changchun, Jilin 130021, China \\ ${ }^{5}$ Department of Gerontology, The First Hospital of Jilin University, Changchun, Jilin 130021, China \\ ${ }^{6}$ Pediatric Research Institute, The Departments of Pediatrics, Radiation Oncology, Pharmacology and Toxicology, The \\ University of Louisville, Louisville, KY 40202, USA \\ "These authors contributed equally to this work
}

Correspondence to: Hongyu Jiang, email: jiang_hy@jlu.edu.cn

Keywords: low dose radiation; hormesis; adaptive response; doxorubicin; oxidative stress

Received: June 24, $2017 \quad$ Accepted: November 26, $2017 \quad$ Published: December 07, 2017

Copyright: Jiang et al. This is an open-access article distributed under the terms of the Creative Commons Attribution License 3.0 (CC BY 3.0), which permits unrestricted use, distribution, and reproduction in any medium, provided the original author and source are credited.

\section{ABSTRACT}

This study aimed to develop a novel and non-invasive approach, low-dose radiation (LDR, 75 mGy X-rays), to prevent doxorubicin (DOX)-induced cardiotoxicity. BALB/c mice were randomly divided into five groups, Control, LDR (a single exposure), Sham (treated same as LDR group except for irradiation), DOX (a single intraperitoneal injection of DOX at $7.5 \mathrm{mg} / \mathrm{kg}$ ), and LDR/DOX (received LDR and $72 \mathrm{~h}$ later received DOX). Electrocardiogram analysis displayed several kinds of abnormal ECG profiles in DOX-treated mice, but less in LDR/DOX group. Cardiotoxicity indices included histopathological changes, oxidative stress markers, and measurements of mitochondrial membrane permeability. Pretreatment of DOX group with LDR reduced oxidative damages (reactive oxygen species formation, protein nitration, and lipid peroxidation) and increased the activities of antioxidants (superoxide dismutase and glutathione peroxidase) in the heart of LDR/DOX mice compared to DOX mice. Pretreatment of DOX-treated mice with LDR also decreased DOX-induced cardiac cell apoptosis (TUNEL staining and cleaved caspase-3) and mitochondrial apoptotic pathway (increased p53, Bax, and caspase- 9 expression and decreased Bcl 2 expression and $\Delta \Psi \mathrm{m}$ dissipation). These results suggest that LDR could induce adaptation of the heart to DOX-induced toxicity. Cardiac protection by LDR may attribute to attenuate DOX-induced cell death via suppressing mitochondrial-dependent oxidative stress and apoptosis signaling.

\section{INTRODUCTION}

Doxorubicin (DOX) is an effective drug commonly used to treat both solid tumors (breast cancer, carcinomas) and hematologic malignancies (leukemia, lymphomas) [1]. The broad usage of DOX for over 50 years has dramatically improved cancer survival statistics. However, the dosedependent cardiotoxicity compromises its clinical usage [2-4]. With the increasing population of cancer survivors, there is a growing need to elucidate the mechanisms for DOX-induced cardiomyopathy and the potential ways to prevent its development and progression. The appreciated mechanisms for DOX-induced cardiomyopathy include oxidative stress, inflammation, dysregulation of calcium handling and cellular contractility, mitochondrial degeneration, and apoptotic cardiomyocyte death [2-5]. However, oxidative stress is the major contributor in triggering and progressing DOX-induced myocardial 
biochemical and pathological changes, leading to the final structural remodeling and dysfunction $[2,6]$.

Based on the concept that free radicals involve in DOX cardiotoxicity, a number of antioxidant compounds were tested in animal models and cancer patients [7-9]. Studies with animal models of cardiac overexpression of certain antioxidants such as catalase and metallothionein have shown the well protection from DOX-induced cardiotoxicity [7, 8]. To date, despite Dexrazoxane, an intracellular iron chelator to reduce the potential generation of iron-derived free radicals, has been approved as a prophylactic medication used in clinical practice for the cancer patients who received DOX treatment [10], the potentially hematological toxicities of Dexrazoxane promotes remains to further search for a better approach that can ameliorate DOX cardiotoxicity without compromising its antineoplastic activity [10]. Current two major concerns include: (a) Exogenous administration of antioxidants could not maintain consistent levels between two dosing [10-13]; therefore, it may be a better way to induce endogenous cardiac antioxidants; (b) Systemic administration of any drug may not only protect against DOX cardiac toxicity, but also reduce the efficacy of DOX cancer therapy [10-13]; therefore, any non-invasive approach that can specifically stimulate cardiac antioxidant capacity may be a better strategy to prevent DOX cardiac toxicity without impact on its cancer therapeutic effects.

We proposed the application of low-dose radiation (LDR) to protect the heart from DOX since LDR could prevent damage to normal tissue induced by radiation and anticancer drugs [14-16]. LDR, which is ubiquitous in our environment, is defined as a radiation dose of $100 \mathrm{mSv}$ or less ( $\leq 100 \mathrm{mGy}$ ). Low-dose-rate radiation is defined as the rate of radiation exposure at $6 \mathrm{mSv}$ or less per hour $(<6 \mathrm{mSv} / \mathrm{h})$. For low linear energy transfer (LET) radiation, $1 \mathrm{~Gy}$ (exposure dose) is equal $1 \mathrm{~Sv}$ (absorbed dose) (see references in review [17]. Distinct from highdose radiation that causes cytotoxic effects in vitro and in vivo, LDR induces an adaptive or hormetic response in cells and tissues, showing a tolerance to subsequently high dose of radiation- or chemical-induced damage in vitro and in vivo [14-16]. Our previous study suggested that LDR stimulated growth of normal cells but not leukemia or solid tumor cells in vitro and LDR also did not stimulate growth of solid tumor cells in vivo [16]. In addition, LDR decreases cancer risks via stimulating anticancer immunity [18-20]. The protective effects of LDR were attributed to up-regulated antioxidants [21] and DNA repair enzymes $[22,23]$. We already demonstrated the protective effect of LDR on various diabetic complications, such as the testicular, renal, and cardiac damages in diabetic rats and mice [24-26]. Therefore, the distinct features of LDR, compared to other compounds discussed above [9-13], include: (a) A non-invasive approach; (b) Applicable to heart area without affecting other organs; (c) Ability to stimulate multiple defense functions; (d) No detectable and obvious side-effect.

In fact, pre-chemotherapeutic LDR was able to alleviate anticancer drug, cyclophosphamide-induced damaging effects on the liver [14]. However, there was no study that has explored whether LDR could provide protective effect against DOX cardiotoxicity in vivo. Therefore, the present study was aimed to develop a novel and non-invasive approach, LDR (75 mGy X-rays), to prevent DOX cardiotoxicity in mice. Considering the fact that LDR is able to attenuate oxidative stress, mitochondrial dysfunction and apoptosis in a rat model of Parkinson's diseases [27, 28], we also examined the cardiac mitochondria and associated oxidative stress and cell death in order to elucidate the underlying mechanisms by which LDR protects the heart from DOX.

\section{RESULTS}

\section{Effect of LDR on DOX-induced cardiotoxicity}

To test whether LDR can attenuate DOX-induced cardiac toxicity we observed the general appearance of the mice, animal survival rate, and changes of ECG. DOXtreated mice were sick and weak, and their fur became scruffy. These changes were less pronounced in LDR/ DOX mice. There was no difference for their appearance among control, sham and LDR mice. The mice in control, sham-irradiated, and LDR groups were $100 \%$ survived, whereas mice in the DOX group showed $80 \%$ and $60 \%$ survival at the 6th and 7th day after treatment. Preexposure of DOX-treated mice to LDR increased animal survival rate to $90 \%$ and $80 \%$ survival rate at the 6th and 7 th days after DOX treatment, respectively (Figure 1A).

Electrocardiogram (ECG) analysis showed normal profiles in the control and LDR groups. However, there are several kinds of abnormal ECG profiles in DOX-treated mice, which were frequently seen in DOX alone group with several kinds of abnormalities, compared to LDR/DOX group. The abnormal ECG changes include arrhythmia, $T$ wave flat, and ST-segment depression. The typical changes of ECG of animals were shown in Figure 1B.

Since increased serum lactate dehydrogenase (LDH) has been often used as the main serum biochemical marker of myocardial damage [29], we further examined the protective effect of LDR pretreatment on DOX-induced cardiotoxicity by detecting serum levels of LDH. As shown in Figure 1C, there was no significant difference of the enzyme levels among the control, the sham-irradiated, and the LDR groups. However, the level of serum LDH was significantly higher in DOX group as compared with that in Sham-irradiated group while pretreatment with LDR attenuated DOX-induced elevation of LDH serum level.

Morphological changes in the heart were also examined by H\&E staining (Figure 1D), which showed that the histology of the heart tissue from control and 
sham-irradiated mice showed normal morphological appearances, whereas in DOX group, myofibrillar disorder and vacuolization of the cytoplasm were observed. The histology of heart tissues from LDR+DOX group showed less myofibrillar disorder and vacuolization of the cytoplasm. Compared with the mice in control group, there was no significant change of myocardial histopathology of mice in LDR group (Figure 1D). These results indicated that DOX can cause significant cardiac toxicity, and LDR effectively resisted DOX-induced cardiotoxicity.

\section{Effect of LDR on DOX-induced myocardial cell death}

Accumulated evidence showed that DOX can cause apoptotic cell death in the animal heart $[5,11,12]$. To test whether LDR-alleviated DOX cardiotoxicity was associated with the reduction of apoptosis we performed TUNEL staining in which green fluorescence indicates apoptosis as shown in Figure 2A. Quantitative analysis for the apoptotic index (AI) shows no or few cells with

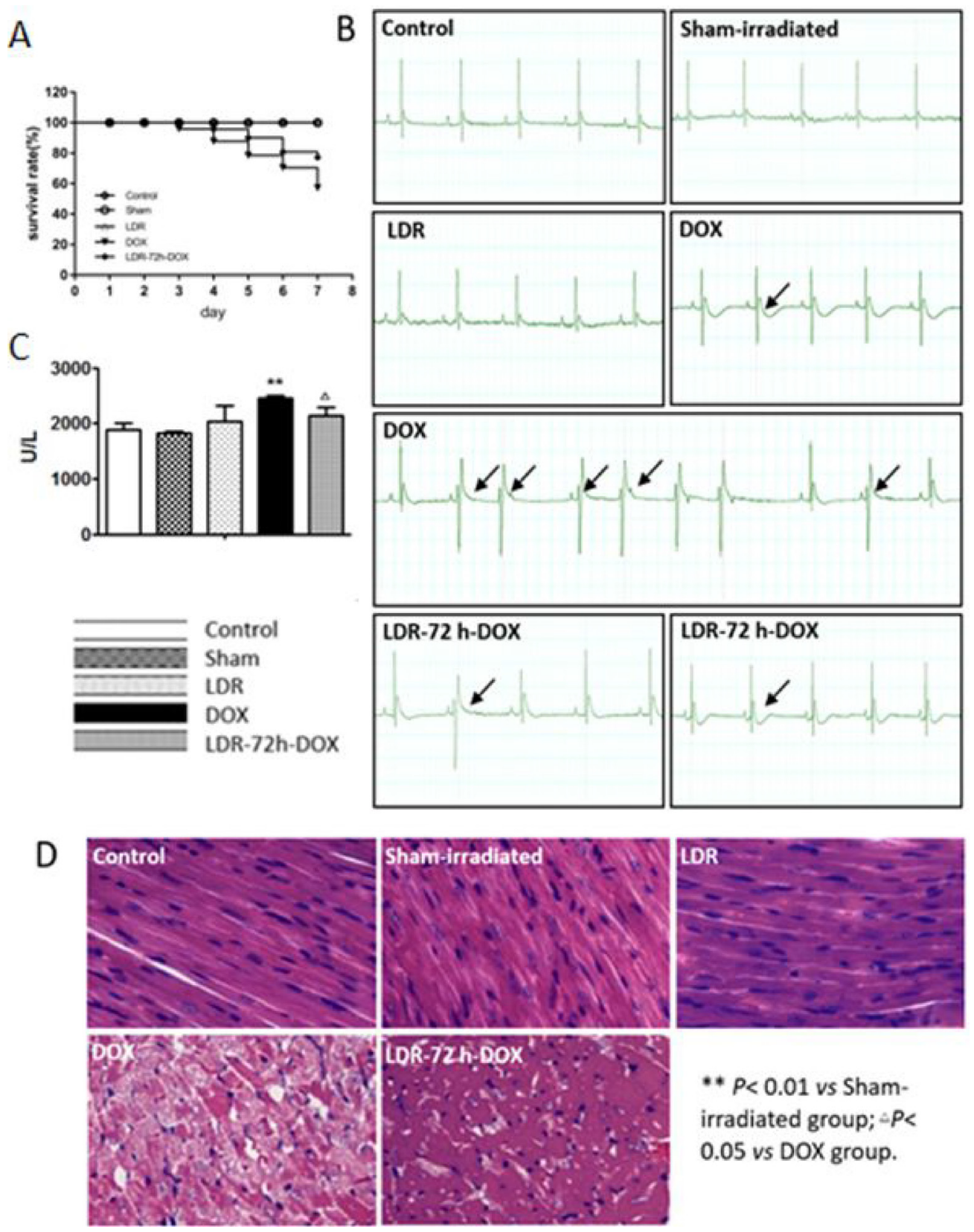

Figure 1: Effect of LDR on DOX-induced animal mortality and cardiotoxicity. (A) Survival rate of the mice in each group at the 5th day after the last DOX injection $(n=10-20)$. (B) Representative ECG results that show several kinds of ECG changes including arrhythmia, T wave flat, and ST-segment depression in DOX-treated mice. (C) LDH activities among different groups of mice. (D) Histopathological changes $(\times 100)$, showing myofibrillar disarrangement and vacuolization of the cytoplasm in the heart of DOXtreated mice. 
green fluorescence in the control, sham-irradiated, and LDR groups. However, intense green fluorescence was observed in DOX group whereas less green fluorescence was seen in LDR/DOX group $(P<0.01)$.

Next the expressing level of cleaved caspase-3, a key mediator of apoptosis, was examined by immunohistochemical staining as shown in Figure 2B, followed by semi-quantitative analysis, show very low level of cleaved caspase-3 among the control, sham-irradiated, and LDR groups, but DOX induces a significant increase in cleaved caspase-3 level, which was remarkable prevented by pre-LDR treatment (Figure 2B). The TUNEL positive cells and cleaved caspase-3 analyses clearly suggested the induction of apoptotic cell death by DOX and DOX-induced apoptotic cell death is significantly prevented by pre-exposure to LDR. The immunohistochemical staining results of cleaved caspase was further confirmed by Western blot analysis (Figure 3).

\section{Effect of LDR on DOX-induced mitochondria- dependent apoptotic pathway}

It was reported that apoptotic markers, such as caspase activation, were detected after $24 \mathrm{~h}$ of DOX treatment and Bax and p53 translocation to mitochondria as well as the formation of Bax clusters in the cytosol [30]. Therefore, we tried to ensure whether LDR-mediated protection from DOX-induced apoptosis is attributed to its prevention of mitochondria-dependent apoptotic pathway. First we examined and confirmed the increased expression

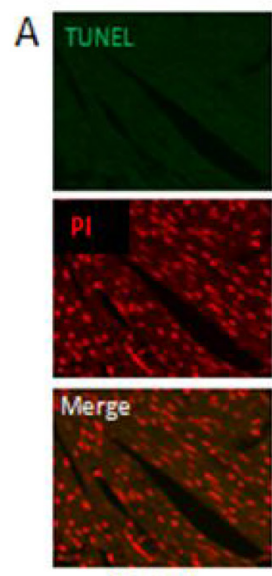

Control
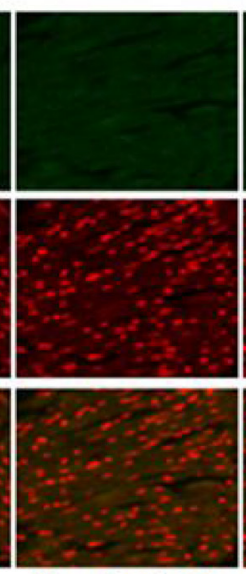

Sham-irradiated
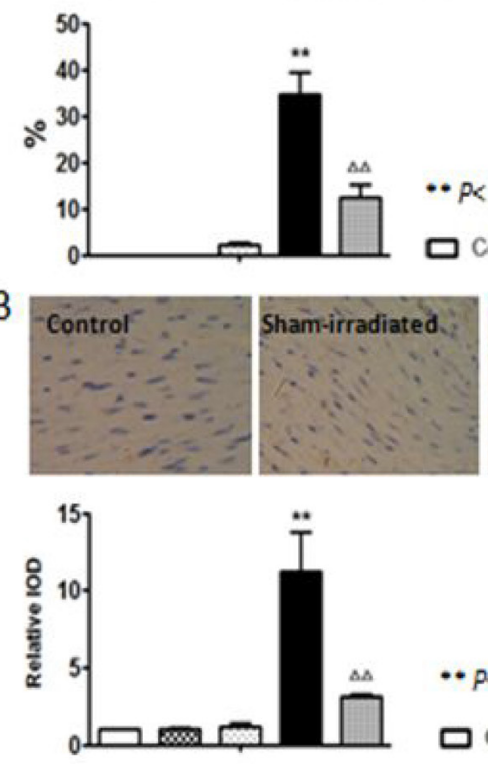
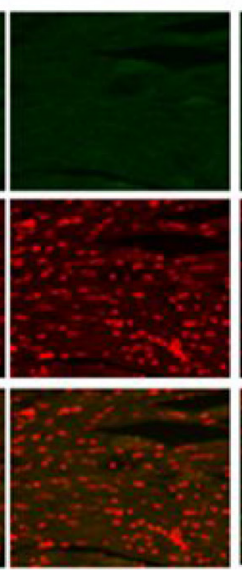

LDR
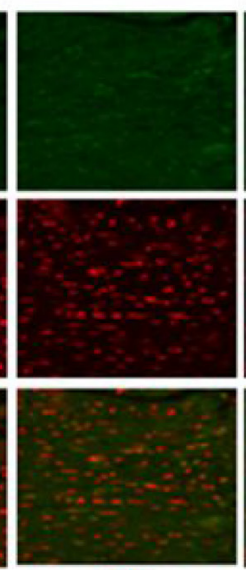

DOX
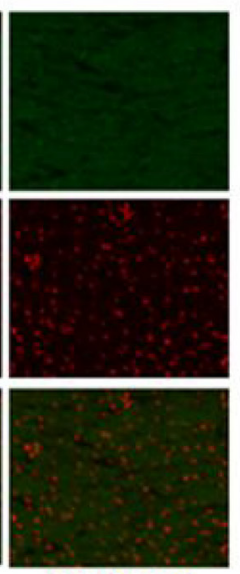

LDR-72 h-DOX

*P< 0.01 vs control group; $\triangle 4 P<0.01$ vs DOX group.
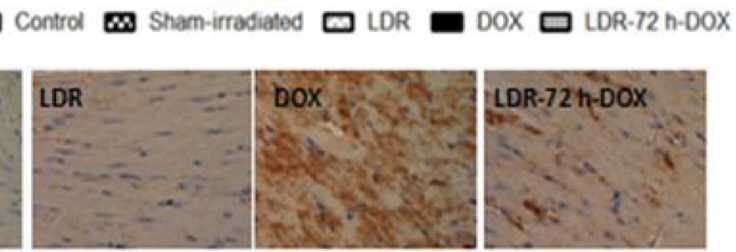

$* p<0.01$ vs control group; $\sim 2 P<0.01$ vs DOX group.

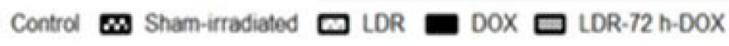

Figure 2: Effect of LDR on DOX-induced myocardial apoptosis. (A) Apoptotic cells were measured by TUNEL assay in which green fluorescence indicates apoptosis, and quantitatively presented as apoptotic index (AI), e.g.: the percentage of TUNEL positive cells. (B) Expression of the cleaved caspase- 3 was determined by immunohistochemical staining $(200 \times)$, where brown color (positive) and light blue color (negative) denotes the cell expressing with or without cleaved caspase-3, respectively. Expression of cleaved caspase-3 was quantitatively analyzed as integrated optical densities (IOD) and presented as relative IOD in experimental group to that of control. Values are expressed as means $\pm \mathrm{SE}(n=6)$. 
of p53 in DOX-treated mice in parallel with the increase in cleaved capaspase-3 (Figure 3), both which were prevented by pre-exposure of DOX-treated cells to LDR.

Second we examine mitochondrial $\mathrm{Bcl} 2$ family antiand pro-apoptotic members: Bcl2 and Bax protein expression with Western blotting assay, which showed no much change for the expression of either Bcl-2 or Bax protein among groups of control, sham-irradiated and LDR mice (Figure 3). However, significantly decreased expression of $\mathrm{Bcl} 2$ and increased expression of Bax were seen in DOX group, but not in LDR/DOX group. The Western blotting results were supported by immunohistochemical staining for both Bcl-2 and Bax expressions, followed by semi-quantitative analysis (Figure 4).

Above assays indicated the involvement of mitochondrial apoptosis pathway in the induction of cardiac cell death by DOX, which promoted us to further detect mitochondrial membrane potential $(\Delta \Psi \mathrm{m})$ with flow cytometry (Figure 5 Top panel). No difference was found for $\Delta \Psi \mathrm{m}$ of the hearts between control and sham groups, but $\Delta \Psi \mathrm{m}$ in the DOX group was significantly lower than that of the sham group. DOX-decreased $\Delta \Psi \mathrm{m}$ level was significantly improved by pre-exposure to LDR in LDR/ DOX group (Figure 5 Top panel).

Caspase-9 as a key mediator for mitochondrial apoptosis pathway was also examined with immunohistochemistry, followed by semi-quantitative analysis (Figure 5 bottom panel). There was no much positive staining among groups of the control, sham and LDR mice, but there was an increase in caspase- 9 expression in DOX group but not in LDR/DOX group.

\section{Effect of LDR on DOX-induced oxidative stress}

Reportedly DOX-triggered the mitochondriadependent apoptotic pathway in cardiomyocytes is predominantly attributed to DOX-induced oxidative stress $[6-9,31]$; accordingly, we evaluated the level of ROS by flow cytometry with the probe of cell permeant DCFH-DA to measure primarily $\mathrm{H}_{2} \mathrm{O}_{2}$ and other ROS. As shown in Figure 6A, 6B, the level of ROS increased significantly in the DOX group compared with the Sham group $(P<0.01)$, whereas the increase by DOX was attenuated by LDR pretreatment. Compared with the Sham group, the level of ROS in LDR group was slightly increased $(P<0.05)$.

As one of oxidative damage index, lipid peroxidation level, shown by malondialdehyde (MDA), was examined (Figure 6C). The level of MDA was not significantly altered in LDR group but increased in DOX group compared with Sham group $(P<0.01)$. Pretreatment of DOX-treated mice with LDR slightly reduced DOXincreased MDA level.

We also measured the activities of SOD and GSHPX (Figure 6D, 6E), which were both decreased in the DOX group compared to the control $(P<0.01)$, whereas DOX-decreased activities of SOD and GSH-PX were reversed by LDR pretreatment. These results suggested that LDR inhibition of DOX-induced oxidative stress and
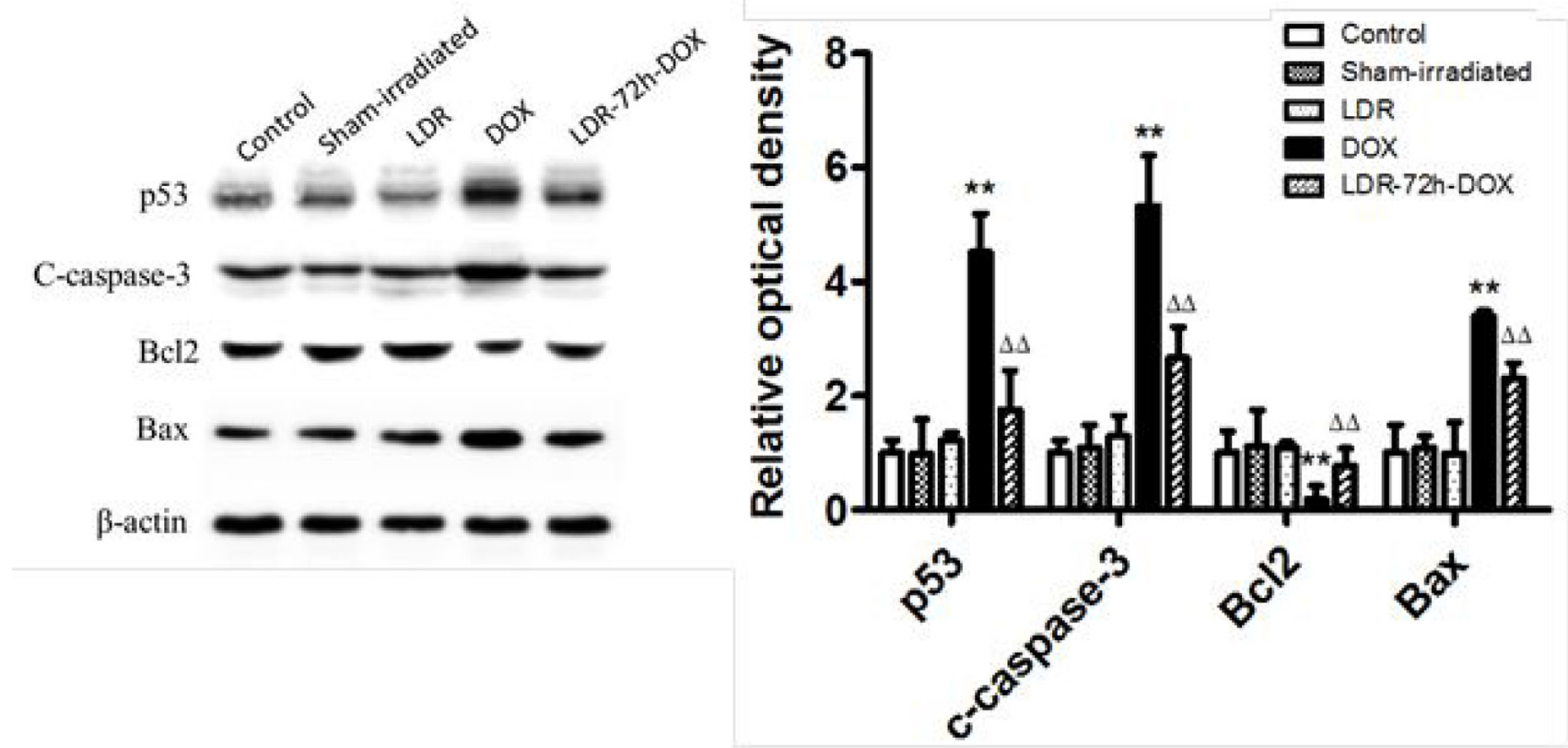

Figure 3: Western blots for the effect of LDR on DOX-induced p53 and mitochondrial apoptotic signaling. Expression of $\mathrm{p} 53$, cleaved caspase-3 (C-capase-3), Bcl2, and Bax protein was examined with Western blots, followed by quantitatively densitometric analysis of the target protein bands. The relative optical density (target protein band density to $\beta$-actin value) was presented as means $\pm \mathrm{SE}$ $(n=6) .{ }^{* *} p<0.01$ vs Sham-irradiated group, ${ }^{\Delta \Delta} p<0.01$ vs DOX group. 
damage might be related to the up-regulated activity of antioxidant enzymes and reduced production of ROS.

Using Western blotting assay, the expression of nuclear factor erythroid 2-related factor 2 (Nrf2) as transcription factor involved in cellular redox homeostasis was further examined along with other oxidative and nitrative variables, including 4-hydroxynonenal (4-HNE) and 3-nitrotyrosine formation (Figure 7). The heart of mice with LDR and sham-irradiation did not exhibit any change of Nrf2, 3-NT and 4-HNE levels; however, heart of mice treated by DOX alone exhibited a decrease in Nrf2 protein level along with increases in 3-NT and 4-HNE accumulation, which were almost completely attenuated by pre-exposure to LDR in LDR/DOX group.

\section{DISCUSSION}

DOX is a powerful antibiotic used to treat a multitude of human neoplasms; however, cardiac toxicity compromises its clinical applications [2-4]. Therefore, the search for a safe and effective approach to prevent or reverse DOX-induced cardiotoxicity remains a critical issue in both cardiology and oncology. Adaptive response or hormesis induced by LDR shows a protective effect
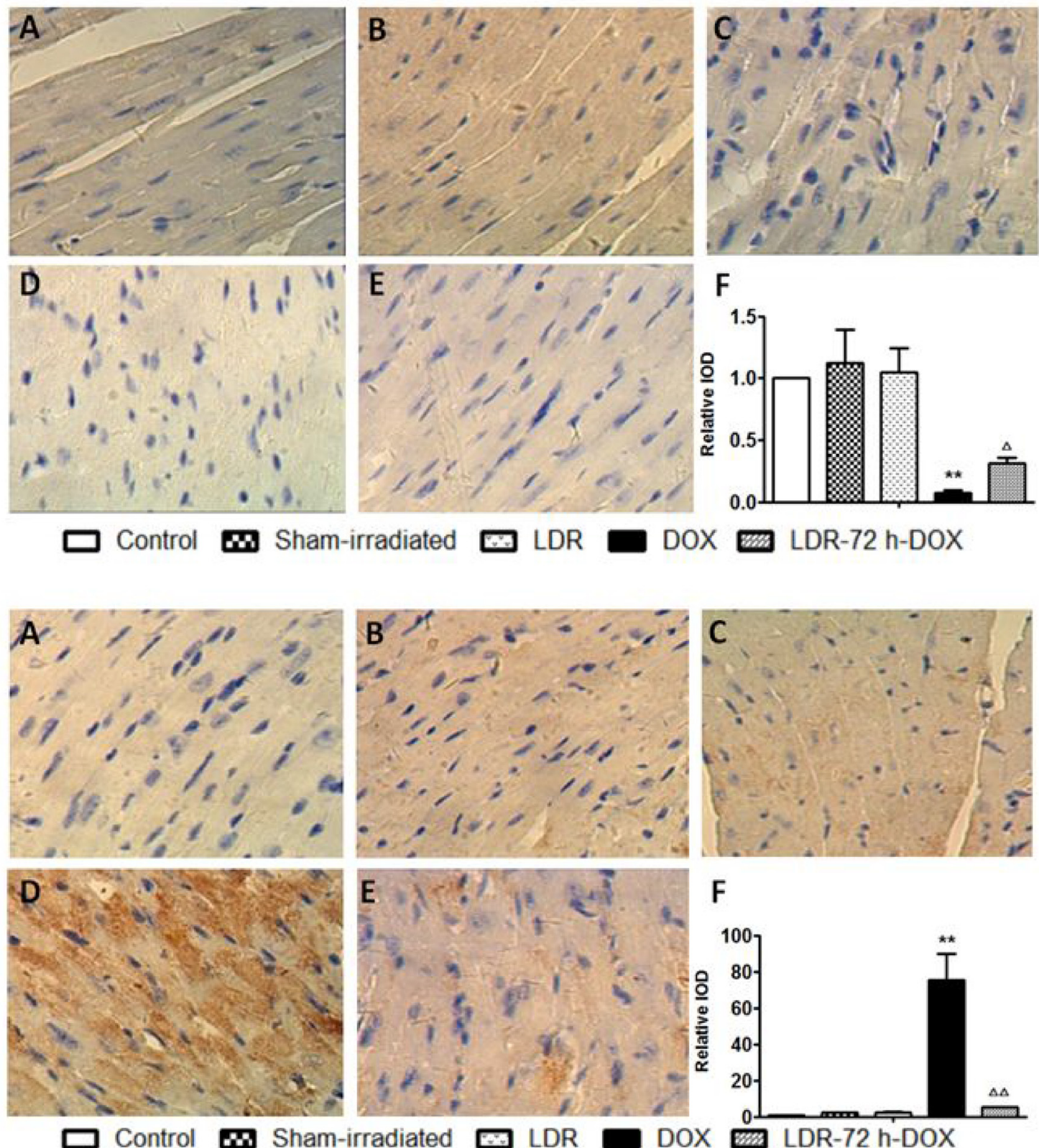

Figure 4: Effect of LDR on DOX-induced mitochondria-dependent apoptotic pathway. Expression of Bcl-2 (Top panel) and Bax (Bottom panel) by immunohistochemical staining $(200 \times)$ was quantitatively analyzed for IOD. Values are expressed as means \pm SE $(n=6)$. The IOD was normalized to the Control. 
on subsequent challenges-induced damage in vitro and in vivo. The present study confirms protective effects of LDR on DOX-induced cardiotoxicity, which may be associated with LDR-stimulated cardiac antioxidant capacity in reducing oxidative stress derived from mitochondria-dependent ROS/ RNS generation, as outline in Figure 8.

In this study, we first evaluated the ameliorating effect of LDR on DOX-induced cardiotoxicity in mice. Previous studies have shown DOX-induced myocardial injuries in animal models and human biopsies, manifested by the significant elevation in activity of serum LDH [29] and damages such as cytoplasmic vacuolization and myofibrillar disorder [32, 33]. Consistent with these previous studies, here we also found DOX-induced cardiotoxicity, reflected by abnormal ECG profiles, increased serum LDH activity, and alterations of histopathology of the heart. However, we demonstrated the prevention of DOX-induced changes, including cardiac function, serum cardiac enzyme and structure by pre-exposure to LDR at $75 \mathrm{mGy}$.

Oxidative stress has been considered a major contributor in DOX-induced myocardial dysfunction [69, 31, 45-48]. To support this notion, mice with cardiac overexpression of catalase and metallothionein are resistant to DOX-induced cardiotoxicity $[7,8]$. Induction of endogenous
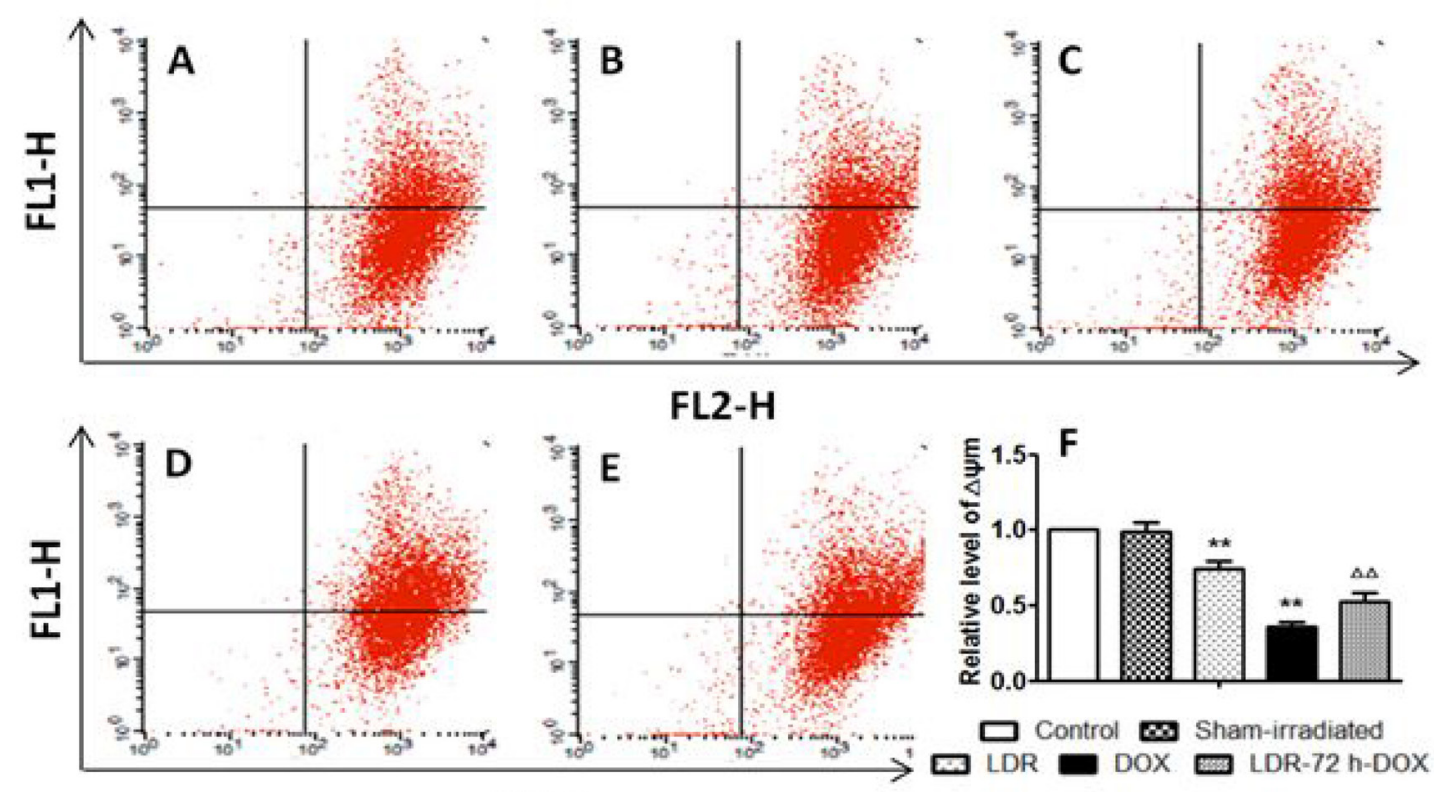

FL2-H
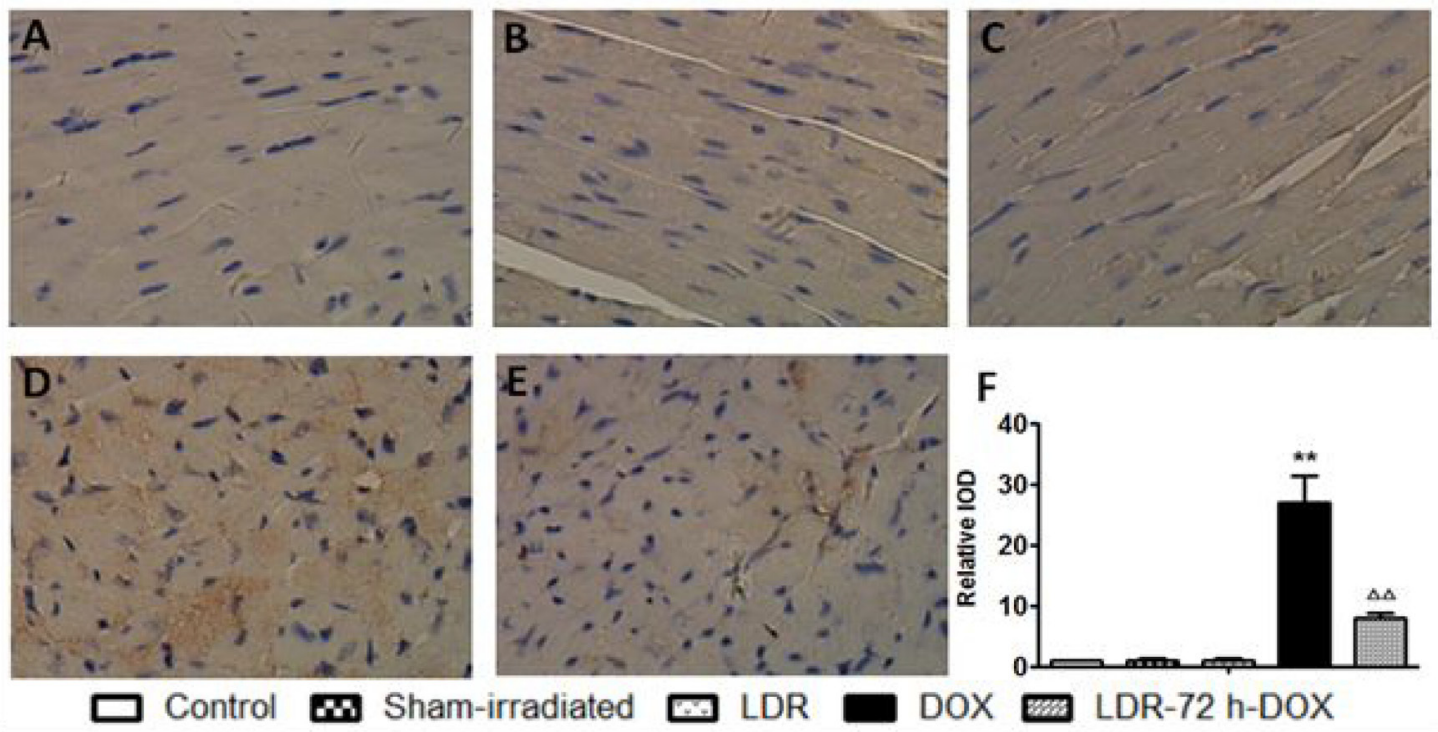

Figure 5: Effect of LDR on DOX-induced mitochondria-dependent apoptotic pathway. (A) Representative profile of flowcytometry and quantitative analysis of the fluorescence intensity of cardiac myocytes after staining with JC-1, measured with flow cytometry. (B) Expression of cleaved caspase-9 by immunohistochemical staining (200×). Quantitative image analysis for immunohistochemical staining expressed as IOD. Values are expressed as means $\pm \mathrm{SE}(n=6)$. The IOD was normalized to the Control. 
antioxidant with procyanidins, extracted from grape seeds also protected from DOX-induced cardiotoxicity [34]. Here we thus explored whether LDR protection against DOXinduced cardiotoxicity is associated with its prevention of oxidative stress and damage. We demonstrated that DOXincreased oxidative stress and damage, shown by increased ROS and oxidative damage are attenuated by pre-exposure to LDR in DOX-treated mice.

Reportedly DOX-induced apoptosis of cardiomyocytes as the most direct cause of DOX cardiotoxicity may be mitochondria-dependent [30, 31, 35]. Studies have shown that mitochondria-dependent apoptotic pathway in cardiomyocytes is mediated by DOX-induced oxidative stress $[6-9,31]$. Oxidative damage to mitochondrial membranes, enzymes, and electron transport chain, which facilitates mitochondrial permeability transition pore opening, changes ${ }^{\triangle} \Psi \mathrm{m}$, and releases cytochrome $\mathrm{c}$ to cytosol, resulting in the activation of caspase-9, to activate its effector caspases, such as caspase-3, to induce cell death [36, 37]. Mitochondriamediated apoptosis is also modulated by the Bcl-2 family of proteins, including pro-apoptotic (e.g. Bax and Bid) and anti-apoptotic (e.g. Bcl-2 and Bcl-xL) members [30, 38]. Increasing the expression of $\mathrm{Bcl}-\mathrm{xL}$ or $\mathrm{Bcl}-2$ can protect against DOX-induced cardiotoxicity [30, 38]. Our study shows that DOX has profound effects on the Bcl-2 family proteins: down-regulating $\mathrm{Bcl}-2$ and up-regulating Bax expression, which is in agreement with previous studies.

In addition, we here show the preventive effect of pre-exposure to LDR on DOX-induced decrease in mitochondrial permeability and increase in caspase- 9 cleavage. Pre-exposure of DOX-treated mice with LDR attenuated DOX-increased ratio of Bax to Bcl-2 expression. A recent study reported that combined preLDR at 0.5 Gy $\gamma$-rays with sea cucumber or valsartan
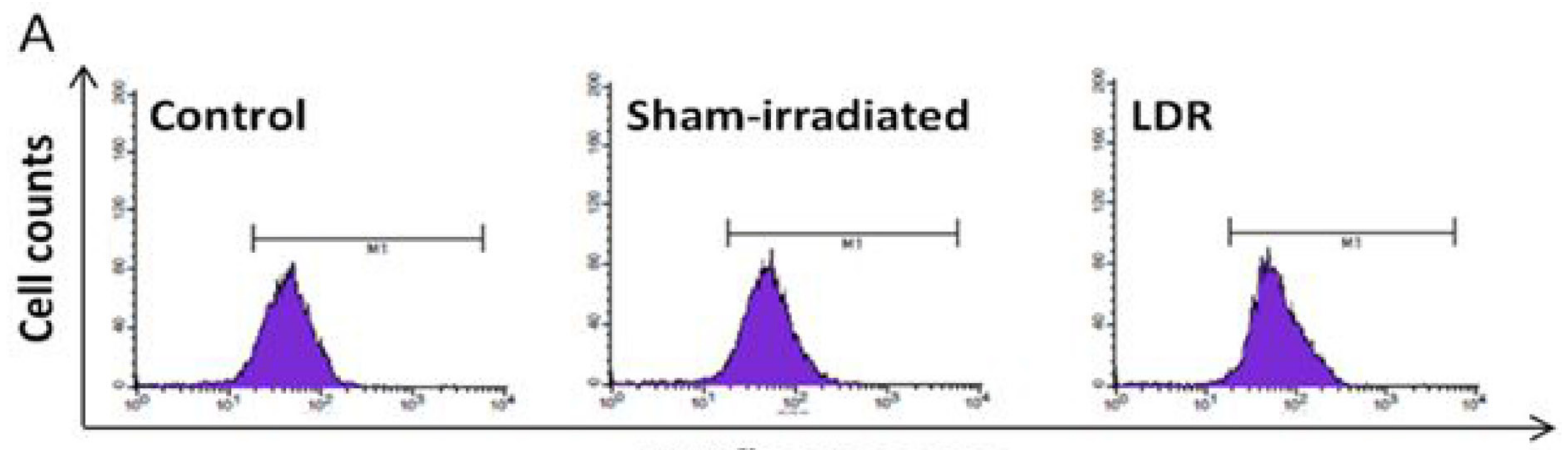

DCF fluorescence
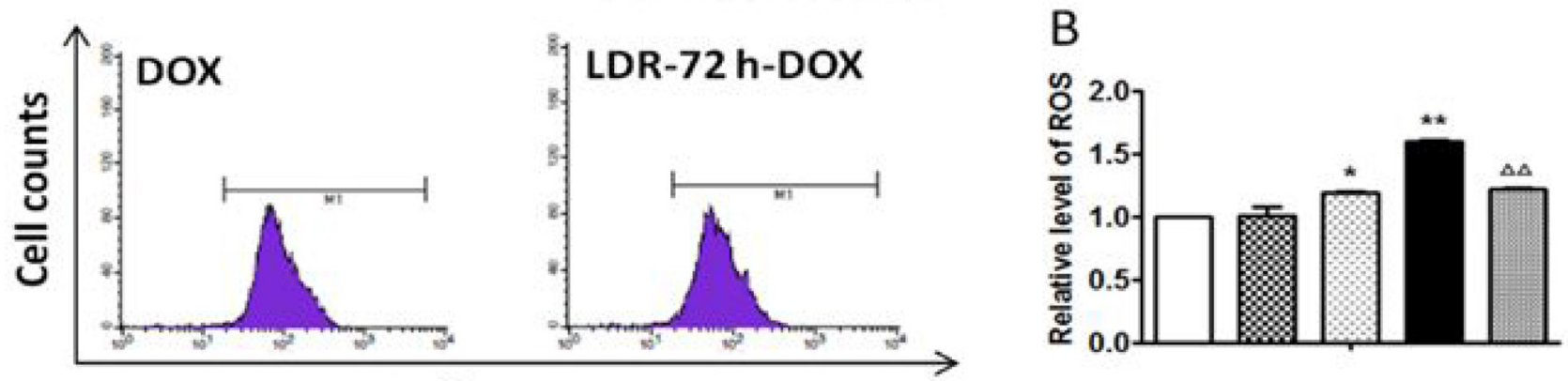

\section{DCF fluorescence}

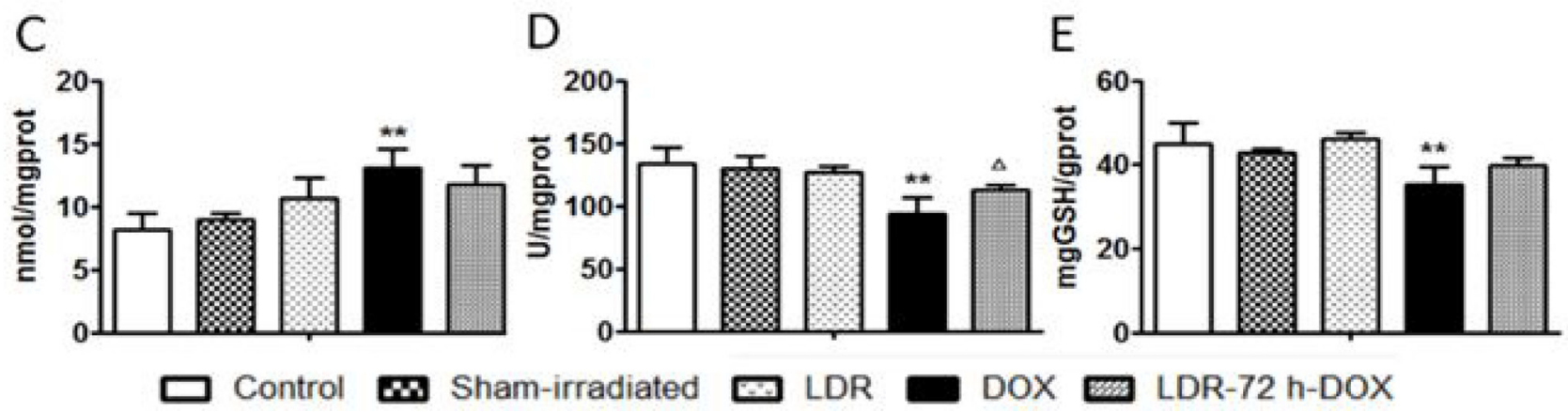

Figure 6: Effect of LDR on DOX-induced oxidative stress. The concentration of intracellular $\mathrm{H}_{2} \mathrm{O}_{2}$ and other ROSs was measured by highly fluorescent DCFH-DA with flow cytometry, and expressed as flow cytometric profiles (A) and graphical columns (B). The level of MDA as lipid peroxidation was measured (C). The activities of both SOD (D) and GSH-PX (E) were also measured with corresponding assay kits. Values are expressed as mean $\pm \mathrm{SE}(n=6),{ }^{*} P<0.05,{ }^{* *} P<0.01$ vs Sham group; ${ }^{\Delta} P<0.05,{ }^{\Delta} P<0.01$ vs DOX group. 
could alleviate DOX-induced cardiotoxicity via inhibiting oxidative stress and apoptosis [39]. However, the dose of 0.5 Gy is not typical LDR $(\sim 100 \mathrm{mGy}$, see references in review [17]). In addition, there was also no comparison between DOX and LDR/DOX groups, since they gave rats $\operatorname{DOX}(2.5 \mathrm{mg} / \mathrm{kg}$, ip) in six equal injections over a period of 2 weeks with and without either sea cucumber (14.4 mg/kg, p.o) or valsartan [30 mg/kg, p.o) for 8 successive weeks. LDR was only given once prior to the first dose of DOX. Therefore, the present study is the first one to show that DOX-induced cardiotoxicity is preventable by pre-exposure to LDT at $75 \mathrm{mGy}$ low LET radiation such as X-rays.

Regarding the mechanisms by which LDR preserves mitochondrial integrity, we do not have direct evidence based on the present study; however we assumed the protective effects of LDR, as illustrated in Figure 8, most likely due to its following reasons: (1) LDR stimulates Akt and Nrf2 functions via generating small amount of ROS $[21,40]$ to up-regulate multiple antioxidants or free radical scavenging capacities $[21,24,40]$; (2) LDR-increased expression of mitochondrial superoxide dismutase $[41,42]$ which may be mediated by LDR-up-regulated Nrf2 transcription function, contributing to the resistance of cardiac cells to DOX; (3) LDR-stimulated mitogen activated protein kinase that turn on cell survival signaling in normal tissues, but not in tumor tissue [40, 43].

In the cells and tissues, small amount of ROS is necessary for cell mitogenic and proliferative functions, while intermediate levels of ROS cause either temporary or permanent cell growth arrest, such as replicative senescence, and severe oxidative stress due to excess ROS
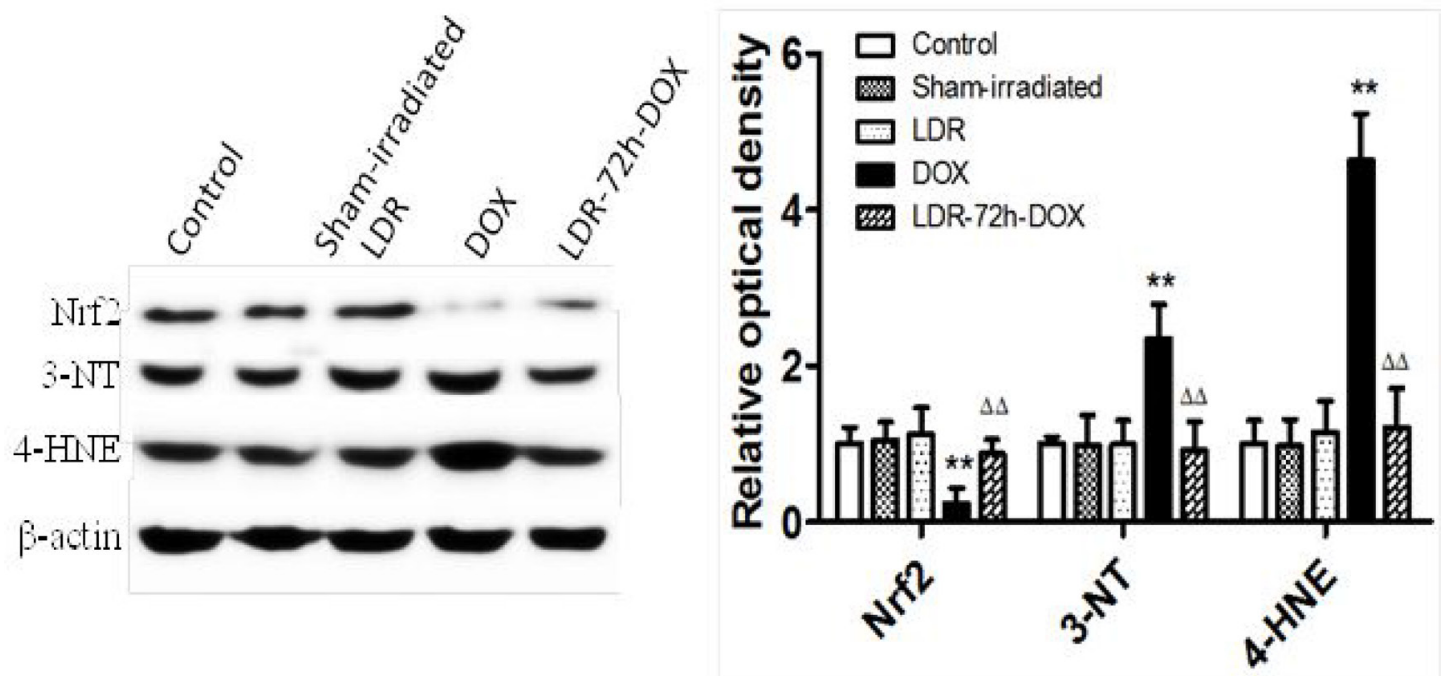

Figure 7: Effect of LDR on DOX-induced oxidative stress associated proteins. Expression of Nrf2, 3-NT, and 4-HNE was analyzed with Western blots, followed by densitometric analysis of the target protein bands. The relative optical density (target protein band density to $\beta$-actin values) was presented as means $\pm \operatorname{SE}(n=6) .{ }^{* *} p<0.01$ vs Sham group, ${ }^{\Delta \Delta} p<0.01$ vs DOX group.

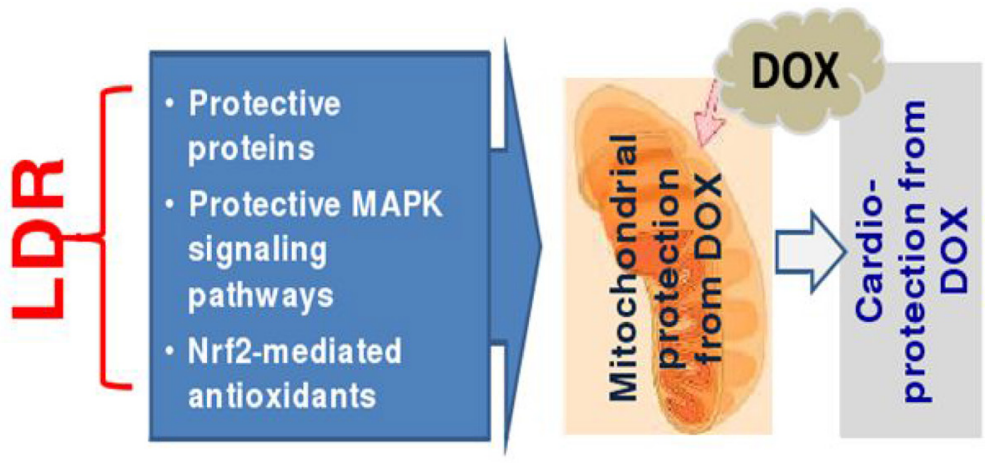

Figure 8: Hypothesized mechanisms by which LDR protects the heart from DOX. Based on previous published work from the authors own and others, we assume that LDR may generate small amount of ROS (a) that stimulates cardiac cells to express protective proteins [21-23]; (b) oxidizes Keap1 to disassociate Nrf2 that translocates to nucleus where Nrf2 transcriptionally up-regulates its downstream antioxidant genes [21, 40-42]; (c) stimulates ERK1/2 or ATM/Akt-mediated protective signaling pathways [21, 43]; All these possible mechanisms protect mitochondrial damage from DOX, resulting in the protection from DOX-induced cardiac cell death and cardiac toxicity. 
ultimately causes cell death [44, 45]. In the present study we found the slight increase in ROS amount in LDR group compared to control, but the remarkable increase in ROS amount in DOX group (Figure 6B). It is known that Keap 1 , which is enriched in cysteine, promotes Nrf2 ubiquitinmediated degeneration. Several compounds, such as sulforaphane (SFN), are able to generate small amount of ROS to oxidize Keap1 to release Nrf2, thereby stabilizing Nrf2 function [46, 47]. Therefore, we assume that LDRgenerated small amounts of ROS may oxidize Keap1, thereby releasing and stabilizing Nrf2 that results in upregulation of multiple antioxidants [21, 40]. However, although both SFN and LDR can generate small amount of ROS to stimulate Nrf2 function, exposure to LDR is noninvasive while SFN must be administrated systemically so that LDR remains the best approach. All these possibilities are summarized in Figure 8.

In summary, to use LDR for preventing cardiotoxicity caused by DOX cancer therapy has the following advantages or novelties: (a) It is a non-invasive approach to stimulate multiple endogenous protective mechanisms; (b) It can be given only cardiac region to stimulate cardiac adaptive or hormetic response without systemic stimulating effect, including cancer tissues. (c) Due to the different growth and metabolic features of tumor cells and normal tissue cells, we can also design LDR doses and interval times between LDR and DOX cancer therapy that all favorite to normal tissue to develop the resistance to DOX. For instance, we have demonstrated that LDR induced adaptive response in normal cells but not in tumor cells under certain conditions $[16,40]$; (d) LDR is able to stimulates anti-tumor immunity in animal model [15, 18-20].

It should be noticed that a recent study reported that LDR at 300 mGy X-rays could increase ischemic limb perfusion recovery and capillary and collateral densities via inducing the expression of proangiogenic genes on mice [48]; since this study used a dose of $300 \mathrm{mGy}$, it is urgent to determine whether radiation at doses of less 200 mGy or even at the dose used in the present study (75 mGy X-rays) will have similar effects remains unclear, but really worthy to be explored. In addition, recently there was a case report that exposure to LDR via computed tomography (CT) scans at a range of 39-47 mGy X-rays was Alzheimer disease [49, 50]; In detail, a 81-year-old patient with Alzheimer disease was admitted to hospice with a life expectancy of less than 6 months, to be treated with CT scans once a while with the request by patient's husband, and then the patient recovered sufficiently to be discharged from hospice on about four months later $[49,50]$; however, more than 2 years after the initial treatment, the patient is in slow decline as described in a late response letter [51]. Although this is the first case that shows the beneficial effect on patient from CT scans, more clinical studies need to be explored for this great potential. Therefore, LDR may be a novel approach to prevent DOXinduced cardiotoxicity and enhance the effectiveness of cancer therapeutics via stimulating multiple functions in the heart without impact on tumors [15, 19, 21, 27, 51].

\section{MATERIALS AND METHODS}

\section{Animals}

$\mathrm{BALB} / \mathrm{c}$ mice (female, weighting $18 \pm 2 \mathrm{~g}$, aged 4-6 weeks) were provided by Animal Experiment Centre of Basic Medical Sciences, Jilin University The experimental protocol was approved by the Animal Ethics Review Committee of Basic Medical Sciences, Jilin University, in accordance with the regulations of the Institutional Committee for the Care and Use of Laboratory Animals. We selected female mice since DOX is mainly used in breast cancer chemotherapy [1]. The mice were maintained and housed under a $12 / 12 \mathrm{~h}$ light/ dark cycle in air-conditioned rooms at $25 \pm 2{ }^{\circ} \mathrm{C}$, with free access to food and water. Animals were accommodated for one week before experimentation.

\section{Drugs and chemicals}

DOX was purchased from Shenzhen Main Luck Pharmaceuticals Inc. (Shenzhen, China). Caspase-9, Caspase-3, Bcl-2, Bax antibodies and secondary antibodies directed against rabbit or goat (HRP-conjugated anti-rabbit or anti-mouse antibody) were purchased from Proteintech Group (Chicago, IL, USA). ROS detection kit for flow cytometry was purchased from Enzo R Life Sciences (Farmingdale, NY, USA). Fluorometric TUNEL system was purchased from Promega (Madison, WI, USA). All chemicals and solvents were of analytical grade.

\section{Radiation conditions}

A Philips deep X-ray machine was used with $200 \mathrm{kVp}, 10 \mathrm{~m}$ A and filters of $0.5 \mathrm{~mm}$ copper plus $1.0 \mathrm{~mm}$ aluminum. The dose rate was $12.5 \mathrm{mGy} / \mathrm{min}$ and the total absorbed dosage was $75 \mathrm{mGy}$.

\section{Experimental designs}

After 1 week of acclimatization, mice were randomly divided into five groups: control $(n=10)$; shamirradiated (sham, mice were treated same as the LDRtreated mice except for irradiation, $n=10$ ); LDR (a single dose of $75 \mathrm{mGy}, n=10$ ), DOX (a single intraperitoneal injection of DOX at $7.5 \mathrm{mg} / \mathrm{Kg}, n=20$ ); LDR+DOX group (mice received LDR of $75 \mathrm{mGy}$ as a pre-treatment and then $72 \mathrm{~h}$ later received DOX administration as in DOX group, $n=20$ ). The general appearance, behavior, and survival rate were observed daily throughout the study. Five days after DOX injection, mice were anesthetized with sodium pentobarbital and subjected to ECG recording with Lab Chart7 Analysis Software (AD Instruments Inc., Australia) to measure arrhythmia. Mice were sacrificed 
for collecting blood and hearts. Then the blood samples that were allowed to clot and serum was separated by centrifugation at $3000 \mathrm{~g}$ for $10 \mathrm{~min}$.

\section{Assessment of cardiotoxicity indices}

Lactate dehydrogenase (LDH) activities were determined with commercially available LDH Kit according to the detail methods provided by the manufacturer's protocol (Nanjing Jiancheng Bioengineering Institute, Nanjing, China).

\section{Histopathological examination}

Heart specimens were fixed in $10 \%$ formalin and processed for paraffin sections of $4 \mu \mathrm{m}$ thickness. Sections were stained with Hematoxylin and Eosin (H\&E) and examined under a light microscope (Olympus BX-50 Olympus Corporation, Tokyo, Japan).

\section{Assessment of oxidative stress markers}

Cardiac tissues were washed with cold saline. The heart tissue was prepared to $10 \%$ (10 g tissue/100 ml saline) homogenate for measuring SOD and GSH-Px activity and MDA content. The activities of SOD and GSH-Px and the content of MDA were determined with their respective assay kits, according to the manufacturer's protocol (Nanjing Jiancheng Bioengineering Institute, Nanjing, China). In brief, the SOD activity was based on the xanthine oxidase method, the GSH-Px activity was determined according to dithio-bis-nitrobenzoic acid (DTNB) chromogenic reaction, and the MDA content was detected by thiobarbituric acid method.

\section{Terminal deoxynucleotidyl transferase biotin-d UTP nick end labeling (TUNEL)}

Nuclear fragmentation was detected by TUNEL staining with an apoptosis detection kit according to the manufacturer's protocol.

\section{Measurement of ROS}

A fluorometric assay was used for the detection of ROS with the fluorescent probe $\left(2^{\prime}, 7^{\prime}\right.$-Dichlorodih ydrofluorescein diacetate, DCFH-DA). DCFH-DA is hydrolyzed by cellular esterases to non-fluorescent $2^{\prime}, 7^{\prime}$-di chlorodihydrofluorescein (DCFH) and then oxidized to fluorescent 2',7'-dichlorofluorescein (DCF) primarily by $\mathrm{H}_{2} \mathrm{O}_{2}$. Since DCFH might also be reactive toward a broad range of oxidizing reactions during intracellular oxidant stress. This probe is widely used to monitor the cellular redox processes. Therefore the generation of ROS in the myocardial cells was evaluated with this this assay based on a previously published method [52]. Briefly, single myocardial cells were incubated in serum-free DMEM.
The homogenate was kept in ice, and centrifuged at $2000 \mathrm{rpm}$ for $5 \mathrm{~min}$. The myocardial cells were washed twice with PBS, and then resuspended at a concentration of $1 \times 10^{6}$ cells $/ \mathrm{mL}$ in serum-free DMEM containing DCFH$\mathrm{DA}$, before incubation at $37^{\circ} \mathrm{C}$ in a hatch box for $20 \mathrm{~min}$. The fluorescent DCF generated in the cells was detected and analyzed with flow cytometry (BD FACSCalibur, San Jose, CA, USA).

\section{Measurement of mitochondrial membrane potential $(\Delta \psi \mathrm{m})$}

Changes in the $\Delta \psi \mathrm{m}$ were measured with a mitochondrial membrane potential assay kit with JC-1 (Beyotime, China), based on published method [52]. When JC-1 exists as J-aggregates in the mitochondrial matrix, it shows red fluorescence and when it exists as monomers in the cytoplasm, it shows green fluorescence. Therefore, the increase in the green fluorescence/red fluorescence intensity ratio, measured as $\Delta \psi \mathrm{m}$, is an indication of increased mitochondrial permeability during mitochondrial depolarization. Briefly, method to isolate the cardiac cells and prepare the single cell suspension was same as those described above. The isolated myocardial cells were incubated with serum-free DMEM containing $5 \mathrm{~g} / \mathrm{mL} \mathrm{JC}-1$ for $30 \mathrm{~min}$. The stained cells were then rinsed twice with serum-free DMEM, fresh serum-free DMEM was added, and the cells were analyzed with flow cytometry with FACSCalibur as described previously [52].

\section{Immunohistochemistry}

All specimens were fixed in 10\% formalin, embedded in paraffin, cut into $4-\mu \mathrm{m}$-thick slides and processed sectioning. For immunohistochemical analysis of Caspase 9, Caspase 3, Bcl-2, and Bax expression, the slides were deparaffinized and rehydrated using standard techniques. Non-specific binding sites were blocked with complete serum at $37^{\circ} \mathrm{C}$ for $30 \mathrm{~min}$. Then, the tissue sections were incubated with the Caspase 9, Caspase 3, Bcl-2, and Bax antibody $(1: 200)$ at $4{ }^{\circ} \mathrm{C}$ overnight. The signal was visualized with peroxidase-labeled streptavidin-complexed DAB, and the sections were briefly counterstained with hematoxylin. Protein positive-staining exhibits a brown cytoplasmic and/ or nuclear stain. Images were captured with the Olympus microscope. The positive cell density was assessed using Image-Pro Plus 6.0 software (Media Cybernetics, Bethesda, MD, USA), and the results are presented as mean optical density (MOD) values. The negative controls were handled in the same way except that PBS was applied in place of a primary antibody.

\section{Statistical analysis}

All results were analyzed using SPSS software, version 19.0 for Windows (SPSS Inc., IL, SA). Data were presented as mean \pm standard Error (SE). One- 
way ANOVA was used for multiple comparisons. $P$ values $<0.05$ were considered as statistically significant.

\section{CONFLICTS OF INTEREST}

The authors declare no competing financial interests.

\section{FUNDING}

This work was supported by the National Natural Science Foundation of China, NSFC [grant number 81272471].

\section{REFERENCES}

1. Tacar O, Sriamornsak P, Dass CR. Doxorubicin: an update on anticancer molecular action, toxicity and novel drug delivery systems. J Pharm Pharmacol. 2013; 65:157-170.

2. Jain D, Russell RR, Schwartz RG, Panjrath GS, Aronow W. Cardiac Complications of Cancer Therapy: Pathophysiology, Identification, Prevention, Treatment, and Future Directions. Curr Cardiol Rep. 2017; 19:36

3. Mc Gowan JV, Chung R, Maulik A, Piotrowska I, Walker JM, Yellon DM. Anthracycline Chemotherapy and Cardiotoxicity. Cardiovasc Drugs Ther. 2017; 31:63-75.

4. Vejpongsa P, Yeh ET. Prevention of anthracycline-induced cardiotoxicity: challenges and opportunities. J Am Coll Cardiol. 2014; 64:938-945.

5. Zhao L, Zhang B. Doxorubicin induces cardiotoxicity through upregulation of death receptors mediated apoptosis in cardiomyocytes. Sci Rep. 2017; 7:44735

6. Simunek T, Sterba M, Popelova O, Adamcova M, Hrdina R, Gersl V. Anthracycline-induced cardiotoxicity: overview of studies examining the roles of oxidative stress and free cellular iron. Pharmacol Rep. 2009; 61:154-171.

7. Kang YJ, Chen Y, Yu A, Voss-Mc Cowan M, Epstein PN. Overexpression of metallothionein in the heart of transgenic mice suppresses doxorubicin cardiotoxicity. J Clin Invest. 1997; 100:1501-1506.

8. Kang YJ, Chen Y, Epstein PN. Suppression of doxorubicin cardiotoxicity by overexpression of catalase in the heart of transgenic mice. J Biol Chem. 1996; 271:12610-12616.

9. Broeyer FJ, Osanto S, Suzuki J, de Jongh F, van Slooten H, Tanis BC, Bruning T, Bax JJ, Ritsema van Eck HJ, de Kam ML, Cohen AF, Mituzhima Y, Burggraaf J. Evaluation of Lecithinized human recombinant super oxide dismutase as cardioprotectant in anthracycline-treated breast cancer patients. Br J Clin Pharmacol. 2014; 78:950-960.

10. Schuler MK, Gerdes S, West A, Richter S, Busemann C, Hentschel L, Lenz F, Kopp HG, Ehninger G, Reichardt P, Pink D. Efficacy and safety of Dexrazoxane (DRZ) in sarcoma patients receiving high cumulative doses of anthracycline therapy-a retrospective study including 32 patients. BMC Cancer. 2016; 16:619
11. Rocha VC, França LS, de Araújo CF, Ng AM, de Andrade CM, Andrade AC, Santos Ede S, Borges-Silva Mda C, Macambira SG, Noronha-Dutra AA, Pontes-deCarvalho LC. Protective effects of mito-TEMPO against doxorubicin cardiotoxicity in mice. Cancer Chemother Pharmacol. 2016; 77:659-62.

12. Kobashigawa LC, Xu YC, Padbury JF, Tseng YT, Yano N. Metformin protects cardiomyocyte from doxorubicin induced cytotoxicity through an AMP-activated protein kinase dependent signaling pathway: an in vitro study. PLoS One. 2014; 9:e104888.

13. Ghosh AK, Rai R, Park KE, Eren M, Miyata T, Wilsbacher LD, Vaughan DE. A small molecule inhibitor of PAI-1 protects against doxorubicin-induced cellular senescence. Oncotarget. 2016; 7:79017-79031. https://doi. org/10.18632/oncotarget.12984.

14. Yu HS, Song AQ, Liu N, Wang H. Effects of low dose preirradiation on hepatic damage and genetic material damage caused by cyclophosphamide. Eur Rev Med Pharmacol Sci. 2014; 18:3889-3897.

15. Blankenbecler R. Low-dose pretreatment for radiation therapy. Dose Response. 2010; 8:534-542.

16. Jiang H, Xu Y, Li W, Ma K, Cai L, Wang G. Low-dose radiation does not induce proliferation in tumor cells in vitro and in vivo. Radiat Res. 2008; 170:477-487.

17. Tang FR, Loke WK, Khoo BC. Low-dose or low-dose-rate ionizing radiation-induced bioeffects in animal models. J Radiat Res. 2017; 58:165-182.

18. Liu SZ. Cancer control related to stimulation of immunity by low-dose radiation. Dose Response. 2006; 5:39-47.

19. Cui J, Yang G, Pan Z, Zhao Y, Liang X, Li W, Cai L. Hormetic response to low-dose radiation: Focus on the immune system and its clinical implications. Int J Mol Sci. 2017; 18:E280.

20. Yang G, Li W, Jiang H, Liang X, Zhao Y, Yu D, Zhou L, Wang G, Tian H, Han F, Cai L, Cui J. Low-dose radiation may be a novel approach to enhance the effectiveness of cancer therapeutics. Int J Cancer. 2016; 139:2157-2168.

21. Xing X, Zhang C, Shao M, Tong Q, Zhang G, Li C, Cheng J, Jin S, Ma J, Wang G, Li X, Cai L. Low-dose radiation activates Akt and Nrf2 in the kidney of diabetic mice: a potential mechanism to prevent diabetic nephropathy. Oxid Med Cell Longev. 2012; 2012:291087

22. Enns L, Rasouli-Nia A, Hendzel M, Marples B, Weinfeld M. Association of ATM activation and DNA repair with induced radioresistance after low-dose irradiation. Radiat Prot Dosimetry. 2015; 166:131-136.

23. Liu SZ, Cai L, Sun JB. Effect of low-dose radiation on repair of DNA and chromosome damage. Acta Biol Hung. 1990; 41:149-157.

24. Zhao H, Xu S, Wang Z, Li Y, Guo W, Lin C, Gong S, Li C, Wang G, Cai L. Repetitive exposures to low-dose X-rays attenuate testicular apoptotic cell death in streptozotocininduced diabetes rats. Toxicol Lett. 2010; 192:356-364. 
25. Zhang C, Tan Y, Guo W, Li C, Ji S, Li X, Cai L. Attenuation of diabetes-induced renal dysfunction by multiple exposures to low-dose radiation is associated with the suppression of systemic and renal inflammation. Am J Physiol Endocrinol Metab. 2009; 297:E1366-1377

26. Zhang C, Jin S, Guo W, Li C, Li X, Rane MJ, Wang G, Cai L. Attenuation of diabetes-induced cardiac inflammation and pathological remodeling by low-dose radiation. Radiat Res. 2011; 175:307-321.

27. Doss M. Low dose radiation adaptive protection to control neurodegenerative diseases. Dose Response. 2014; 12:277-287.

28. El-Ghazaly MA, Sadik NA, Rashed ER, Abd-El-Fattah AA. Neuroprotective effect of EGb761(R) and low-dose wholebody gamma-irradiation in a rat model of Parkinson's disease. Toxicol Ind Health. 2015; 31:1128-1143.

29. Rajadurai M, Stanely Mainzen Prince P. Preventive effect of naringin on cardiac markers, electrocardiographic patterns and lysosomal hydrolases in normal and isoproterenolinduced myocardial infarction in Wistar rats. Toxicology. 2007; 230:178-188.

30. Sardão VA, Oliveira PJ, Holy J, Oliveira CR, Wallace KB. Doxorubicin-induced mitochondrial dysfunction is secondary to nuclear p53 activation in H9c2 cardiomyoblasts. Cancer Chemother Pharmacol. 2009; 64:811-270.

31. Granados-Principal S, El-Azem N, Pamplona R, RamirezTortosa C, Pulido-Moran M, Vera-Ramirez L, Quiles JL, Sanchez-Rovira P, Naudi A, Portero-Otin M, Perez-Lopez P, Ramirez-Tortosa M. Hydroxytyrosol ameliorates oxidative stress and mitochondrial dysfunction in doxorubicininduced cardiotoxicity in rats with breast cancer. Biochem Pharmacol. 2014; 90:25-33.

32. Billingham ME, Mason JW, Bristow MR, Daniels JR. Anthracycline cardiomyopathy monitored by morphologic changes. Cancer Treat Rep. 1978; 62:865-872.

33. Bristow MR, Mason JW, Billingham ME, Daniels JR. Doxorubicin cardiomyopathy: evaluation by phonocardiography, endomyocardial biopsy, and cardiac catheterization. Ann Intern Med. 1978; 88:168-175.

34. Li W, Xu B, Xu J, Wu XL. Procyanidins produce significant attenuation of doxorubicin-induced cardiotoxicity via suppression of oxidative stress. Basic Clin Pharmacol Toxicol. 2009; 104:192-197.

35. Kalyanaraman B, Joseph J, Kalivendi S, Wang S, Konorev E, Kotamraju S. Doxorubicin-induced apoptosis: implications in cardiotoxicity. Mol Cell Biochem. 2002; 234-235:119-124.

36. Camara AK, Bienengraeber M, Stowe DF. Mitochondrial approaches to protect against cardiac ischemia and reperfusion injury. Front Physiol. 2011; 2:13

37. Cook SA, Sugden PH, Clerk A. Regulation of bcl-2 family proteins during development and in response to oxidative stress in cardiac myocytes: association with changes in mitochondrial membrane potential. Circ Res. 1999; 85:940-949.
38. Shan YX, Liu TJ, Su HF, Samsamshariat A, Mestril R, Wang PH. Hsp10 and Hsp60 modulate Bcl-2 family and mitochondria apoptosis signaling induced by doxorubicin in cardiac muscle cells. J Mol Cell Cardiol. 2003; 35:1135-1143.

39. Ibrahim DM, Radwan RR, Abdel Fattah SM. Antioxidant and antiapoptotic effects of sea cucumber and valsartan against doxorubicin-induced cardiotoxicity in rats: The role of low dose gamma irradiation. J Photochem Photobiol B. 2017; 170:70-78.

40. Yang G, Yu D, Li W, Zhao Y, Wen X, Liang X, Zhang X, Zhou L, Hu J, Niu C, Tian H, Han F, Chen X, et al. Distinct biological effects of low-dose radiation on normal and cancerous human lung cells are mediated by ATM signaling. Oncotarget. 2016; 7:71856-71872. https://doi. org/10.18632/oncotarget.12379.

41. Fan M, Ahmed KM, Coleman MC, Spitz DR, Li JJ. Nuclear factor-kappa B and manganese superoxide dismutase mediate adaptive radioresistance in low-dose irradiated mouse skin epithelial cells. Cancer Res. 2007; 67:3220-3228.

42. Eldridge A, Fan M, Woloschak G, Grdina DJ, Chromy BA, Li JJ. Manganese superoxide dismutase interacts with a large scale of cellular and mitochondrial proteins in lowdose radiation-induced adaptive radioprotection. Free Radic Biol Med. 2012; 53:1838-1847.

43. Premkumar K, Shankar BS. Involvement of MAPK signalling in radioadaptive response in $\mathrm{BALB} / \mathrm{c}$ mice exposed to low dose ionizing radiation. Int J Radiat Biol. 2016; 92:249-262.

44. Martindale JL, Holbrook NJ. Cellular response to oxidative stress: signaling for suicide and survival. J Cell Physiol. 2002; 192:1-15.

45. Garlid AO, Jaburek M, Jacobs JP, Garlid KD. Mitochondrial reactive oxygen species: which ROS signals cardioprotection? Am J Physiol Heart Circ Physiol. 2013; 305:H960-968.

46. Bai Y, Wang X, Zhao S, Ma C, Cui J, Zheng Y. Sulforaphane protects against cardiovascular disease via Nrf2 activation. Oxid Med Cell Longev. 2015; 2015:407580

47. Russo M, Spagnuolo C, Russo GL, Skalicka-Woźniak K, Daglia M, Sobarzo-Sánchez E, Nabavi SF, Nabavi SM. Nrf2 targeting by sulforaphane: A potential therapy for cancer treatment. Crit Rev Food Sci Nutr. 2016; 21:1-15

48. Ministro A, de Oliveira P, Nunes RJ, Dos Santos Rocha A, Correia A, Carvalho T, Rino J, Faísca P, Becker JD, GoyriO’Neill J, Pina F, Poli E, Silva-Santos B, et al. Low-dose ionizing radiation induces theraprutic neovascularization in pre-clinical model of hindlimb ischemia. Cardiovasc Res. 2017; 113:783-794.

49. Cuttler JM, Moore ER, Hosfeld VD, Nadolski DL. Treatment of Alzheimer Disease with CT Scans: A Case Report. Dose Response. 2016; 14:1559325816640073. 
50. Cuttler JM, Moore ER, Hosfeld VD, Nadolski DL. Update on a patient with Alzheimer disease treated with CT scans. Dose Response. 2017; 15:1559325817693167.

51. Cuttler JM. Response to Commentary: Treating Alzheimer dementia with CT-induced low-dose ionizing radiation: Problematic, yet potential for more precise inquiry. Dose Response. 2017; 15:1559325817729248.
52. Du Y, Meng Y, Zhu J, Kang L, Jia X, Guo L, Zhang L, Ye M, Hu L, Zhao X, Gu J, Yang B, Zou H. Quantitative proteomic study of myocardial mitochondria in urea transporter B knockout mice. Proteomics. 2014; 14:2072-2083. 